\title{
Kinetics of Extraction of $\beta$-Carotene from Tray Dried Carrots by Using Supercritical Fluid Extraction Technique
}

\author{
Kamalpreet Kaur $^{1}$, Uma Shanker Shivhare ${ }^{1 *}$, Santanu Basu ${ }^{1}$, G. S. Vijaya Raghavan ${ }^{2}$ \\ ${ }^{1}$ University Institute of Chemical Engineering and Technology, Panjab University, Chandigarh, India; ${ }^{2}$ Department of Bioresource \\ Engineering, Macdonald Campus of McGill University, Montreal, Canada. \\ Email: *usshiv@yahoo.com
}

Received November $26^{\text {th }}, 2011$; revised January $30^{\text {th }}, 2012$; accepted February $8^{\text {th }}, 2012$

\begin{abstract}
$\beta$-carotene acts as an antioxidant and is receiving growing interest due to its ability as protecting agent against heart diseases, cancer and strengthening effect on red blood cells. The main aim of this work was to study the kinetics of the supercritical fluid extraction of $\beta$-carotene from tray dried carrots at $40^{\circ} \mathrm{C}, 50^{\circ} \mathrm{C}$ and $55^{\circ} \mathrm{C}$ and 30,35 and $40 \mathrm{MPa}$ at $\mathrm{SC}-\mathrm{CO}_{2}$ flow rate of $2.0 \mathrm{~L} / \mathrm{min}$ for extraction time of up to $6 \mathrm{~h}$. It was observed that the concentration of $\beta$-carotene in the extract increased with pressure, temperature and extraction time. The results indicated that yield was found to be maximum at $45^{\circ} \mathrm{C}$ and $35 \mathrm{MPa}$ at $2 \mathrm{~L} / \mathrm{min} \mathrm{SC}-\mathrm{CO}_{2}$ flow rate. Concentration of $\beta$-carotene in the extract increased with $\mathrm{SC}-\mathrm{CO}_{2}$ flow rate. Weibull distribution model described adequately the kinetics of extraction of $\beta$-carotene from carrots.
\end{abstract}

Keywords: $\beta$-Carotene; Kinetics; Supercritical Fluid Extraction; Carrots; Weibull Distribution Model

\section{Introduction}

Carotenoids are one of the major groups of natural pigments that find widespread utilization in the food industry due to their nutritional and colorant properties [1]. These pigments are fat-soluble and present in wide variety of fruits and vegetables like carrots, peaches, banana skins, tomatoes, red pepper, paprika, sweet potatoes, etc. as well as other parts of plants e.g. in yellow, orange and red flowers. The carotene content of carrots ranges from $600-1200 \mu \mathrm{g} / \mathrm{g}$, while some varieties may contain up to $3000 \mu \mathrm{g} / \mathrm{g}$ [2]. Carotenoids play an important role as food ingredients due to their provitamin A activity and antioxidant function. This antioxidant activity is associated with the reduced risk of lung and colon cancers. $\beta$-carotene is a terpene and is most common form of carotenoid. It is a red-orange pigment abundant in plants and fruits, peculiarly in carrot. $\beta$-carotene is converted to retinol, which is essential for vision and is subsequently converted to retinoic acid, which is used for processes involving growth and cell differentiation. The $\beta$-carotene content is about $80 \%$ of the total carotenoids present in the carrot [2].

Extraction of carotenoids may be accomplished by traditional solvent extraction (TSE) and supercritical fluid extraction (SCFE). Conventional methods are usually carried out at high temperatures, at which destruction "Corresponding author. of valuable substances may be significant. Additionally, use of organic solvents can also lead to product contamination with solvent residues [3]. Traditional extraction methods used to obtain the products have several drawbacks; they are time consuming, laborious, have low selectivity and low extraction yields. Supercritical fluid extraction technique provides higher selectivity, shorter extraction times and no use of toxic organic solvents. It also provides high solubility, improved mass transfer rates, and increased selectivity with small changes in process temperature and pressure [4]. The list of substances that have been proposed as SCFE solvents include: carbon dioxide $\left(\mathrm{CO}_{2}\right)$, ethylene, ethane, nitrous oxide, propane, hexane, methanol, acetone, toluene, pyridine, and water [5]. Supercritical extraction of natural products with $\mathrm{CO}_{2}$ as supercritical fluid is most widely used technique that has a low environmental impact due to the undisputed advantages of carbon dioxide as a solvent, i.e. inertness, non-toxicity, non-flammability, nonexplosiveness, and availability with high purity at low cost and easy separation from extracts [6].

Several studies have been reported in literature dealing with SCFE of $\beta$-carotene from various biological materials including carrot $[1,7]$. However, systematic investigation to determine concentration of $\beta$-carotene at equilibrium $\left(\mathrm{C}_{\infty}\right)$, effect of temperature, pressure, and solvent flow rate to describe the process is lacking. The objective 
of this work is to study the kinetics of extraction of $\beta$ carotene from tray dried carrots using supercritical fluid extraction technique at various levels of temperature, pressure, solvent flow rate and time.

\section{Materials and Method}

Carrots were procured from local market in large quantity to ensure uniformity. They were cleaned under tap water to remove adhering soil and impurities. Cleaned fresh carrots were peeled, sliced into small pieces, thoroughly mixed, weighed, and immediately analyzed for moisture content and $\beta$-carotene.

\subsection{Sample Preparation}

Carrot slices were dried at $40^{\circ} \mathrm{C}$ in a tray dryer for $48 \mathrm{~h}$. Dried slices were ground using a laboratory grinder and screened through a sieve of $1.6 \mathrm{~mm}$ aperture size. Dried and ground sample was analyzed for moisture content and $\beta$-carotene content. The sample was kept in an airtight container at $-20^{\circ} \mathrm{C}$ until used. Desired amount of sample was taken from freezer at least $2 \mathrm{~h}$ before start of extraction of $\beta$-carotene.

\subsection{Moisture Content}

Moisture content was determined by drying the sample in hot air oven at $103^{\circ} \mathrm{C} \pm 1^{\circ} \mathrm{C}$ for $12-13 \mathrm{~h}$ to reach constant weight. Moisture content of fresh, tray-dried, and extracted carrots was determined and expressed on dry matter basis.

\subsection{Supercritical Fluid Extraction}

Supercritical fluid extraction experiments were performed in Speed SFE (Applied Separations, PA, USA) under selected operating conditions. About $30 \mathrm{~g}$ ground carrot sample was transferred into the vessel and extraction was carried out using food-grade $\mathrm{CO}_{2}(>99.8 \%$ pure $)$ as the solvent. The loaded vessel was placed in the convection oven that was set at the desired temperature. Extraction of $\beta$-carotene using the SCFE system was investigated at three levels of temperature $\left(40^{\circ} \mathrm{C}, 50^{\circ} \mathrm{C}\right.$ and $\left.55^{\circ} \mathrm{C}\right)$ and three levels of pressure $(30,35$ and $40 \mathrm{MPa})$. The flow rate was maintained at $2.0 \mathrm{~L} / \mathrm{min}$. Kinetics of $\beta$-carotene extraction was investigated by extracting the samples for 5, 10, 15, 20, 30, 45, 60, 90, 120, 180 and $360 \mathrm{~min}$. Extraction was continued for the desired period and each time new sample was loaded for the kinetic study. Extraction from the solids consists of dissolution of extractable material within the matrix and transfer to the bulk fluid. The mass transfer proceeds by diffusion through the matrix structures or pores, up to the bulk fluid where the components are swept along to the extractor outlet [1]. The extracted crude from the extractor needle was collected in a glass vial and weighed. In order to collect parts of solutes that could have precipitated during depressurization, the needle valve was flushed with the liquid mixture. Analysis of the collected extract was carried out by using U.V-Spectrophotometer (Shimadzu Corp., Japan).

\section{4. $\beta$-Carotene Estimation}

The $\beta$-carotene content for fresh, tray dried and spent carrot was evaluated by solvent extraction method. The sample was weighed and $5-10 \mathrm{~mL}$ of acetone, few crystal of sodium sulphate and $5-10 \mathrm{~mL}$ of distilled water was added in mortar to facilitate grinding. Petroleum ether $(15-20 \mathrm{~mL})$ was used to extract $\beta$-carotene. Ether layer was removed using pipette, filtered and filtrate was collected into volumetric flask. Process was repeated till solvent layer became colorless and volume was made-up using petroleum ether. The absorbance value at $452 \mathrm{~nm}$ using $3 \%$ acetone in petroleum ether as blank was measured. The $\beta$-carotene in crude extract was analyzed by calculating its absorbance value at $452 \mathrm{~nm}$ after diluting by weight $(0.3 \%$ acetone and $3.7 \%$ petroleum ether). Each experiment was replicated thrice and average values were used in analysis. The concentration of $\beta$-carotene was calculated from the standard curve of U.V-Spectrophotometer (shown in Figure 1) by using the Equation (1):

$$
y=0.266 x+0.019\left(R^{2}=0.997\right)
$$

\subsection{Kinetics of $\boldsymbol{\beta}$-Carotene}

Various mathematical models have been used to study of kinetics of extraction $[1,8]$. These include 1) Logarithmic model (Equation (2)); 2) Two-term diffusion model (Equation (3)); and 3) Weibull distribution model (Equation (4)). Fick's law was not used in this study due to considerable variation in particle size of the ground sample.

$$
\frac{\mathrm{C}-\mathrm{C}_{\infty}}{\mathrm{C}_{\infty}}=\exp (-\mathrm{kt})
$$

where, $\mathrm{C}$ is concentration of $\beta$-carotene in the extract

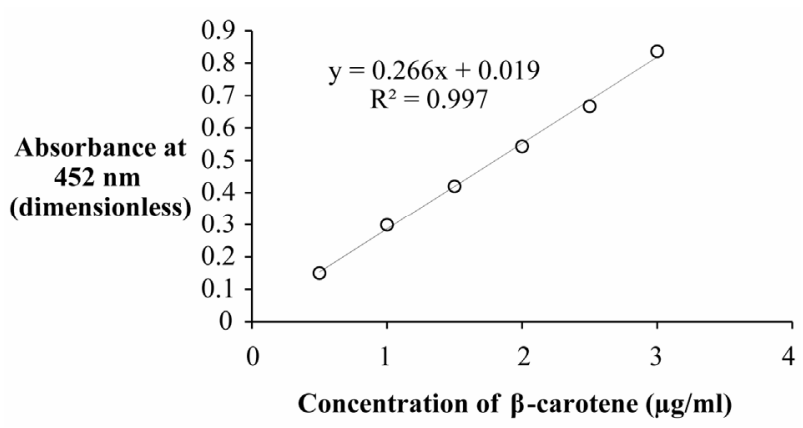

Figure 1. Standard plot for concentration of $\boldsymbol{\beta}$-carotene. $(\mu \mathrm{g} / \mathrm{g})$ at time $\mathrm{t}=\mathrm{t} ; \mathrm{C}_{\infty}$ is the concentration of $\beta$-carotene 
in the extract $(\mu \mathrm{g} / \mathrm{g})$ at time $\mathrm{t}=\infty$; $\mathrm{k}$ is extraction rate $\left(\mathrm{h}^{-1}\right)$; and, $\mathrm{t}$ is the time $(\mathrm{h})$. Sometimes, it is necessary to consider two parallel diffusion processes inside the solid, with two different rate constants. Two-term diffusion model is expressed as:

$$
\frac{C-C_{\infty}}{C_{\infty}}=f_{1} \exp \left(-k_{1} t\right)+f_{2} \exp \left(-k_{2} t\right)
$$

where, $f_{1}$ is the fraction of solute which is extracted with a rate constant $\mathrm{k}_{1}$; and, $\mathrm{f}_{2}$ is the fraction extracted with a rate constant $k_{2}$. Weibull distribution model is expressed as:

$$
\frac{\mathrm{C}-\mathrm{C}_{\infty}}{\mathrm{C}_{0}-\mathrm{C}_{\infty}}=\exp \left(-\mathrm{kt}^{\mathrm{n}}\right)
$$

where, $\mathrm{n}$ is dimensionless coefficient. Linear regression of Equation (2) was carried out using Microsoft Office Excel 2007.Ink; while nonlinear regression of Equations (3) and (4) was done using STATISTICA 6.

Concentration of $\beta$-carotene at equilibrium $\left(\mathrm{C}_{\infty}\right)$ was experimentally determined. It was found that it takes $6 \mathrm{~h}$ to reach the extraction process to equilibrium. Kinetics study was therefore conducted for up to $6 \mathrm{~h}$ at selected levels of supercritical pressure and temperature.

\section{Results and Discussion}

Moisture content of fresh, tray dried, and spent carrot (after extraction) was found to be $891.91 \% \pm 8 \%, 10.32 \%$ $\pm 2 \%$, and $8.95 \% \pm 1 \%$ (dry basis) respectively. It may be observed that some moisture was also diffused into the crude extract as evidenced by lower moisture content in the spent material as compared to that in the ground carrot being loaded in the extractor. Initial $\beta$-carotene content of fresh carrot was $650-700 \mu \mathrm{g} / \mathrm{g}$ (dry matter), while it decreased to about 55 to $70 \mu \mathrm{g} / \mathrm{g}$ (dry matter) after drying at $40^{\circ} \mathrm{C}$ for $48 \mathrm{~h}$ in a tray dryer. It may therefore be inferred that $\beta$-carotene is highly heat labile and about $90 \%$ degradation occurred while carrots were dried at $40^{\circ} \mathrm{C}$ for $48 \mathrm{~h}$. This observation indicates that carrots should be either freeze dried or vacuum dried to minimize $\beta$-carotene loss during pretreatment step. $\beta$ carotene content of spent material (after extraction for 6 h) was found to be about10 $\mu \mathrm{g} / \mathrm{g}$ (dry matter), indicating that it is not feasible to extract all the $\beta$-carotene present in carrots even after $6 \mathrm{~h}$ using SCFE process. This may be due to the fact that fraction of $\beta$-carotene may be chemically combined with other compounds in carrot [2].

Extraction of $\beta$-carotene increased with time at a given temperature and pressure. It was observed that Equation (2) did not fit the data at selected temperatures and pressures. Two-term diffusion model Equation (3) was subsequently tested to analyze the kinetics of extraction of $\beta$-carotene from carrots. It was observed that Equation (3) described well the kinetics of extraction of $\beta$-carotene from carrots for the entire range of supercritical temperature and pressures used in the present study (Figure 2). The coefficients of regression of Equation (3) are reported in Table 1. The $\mathrm{R}^{2}$ values were greater than 0.99 while the standard error values were less than 0.023 in all cases.

The Weibull distribution (Equation (4)) also adequately described the kinetic behavior well as shown in Figure 3. The $\mathrm{R}^{2}$ values were greater than 0.97 while the standard error values were less than 0.019 in all cases.

It may therefore be inferred that both two-term model and Weibull distribution model described the kinetics of extraction of $\beta$-carotene from carrots. The appropriate

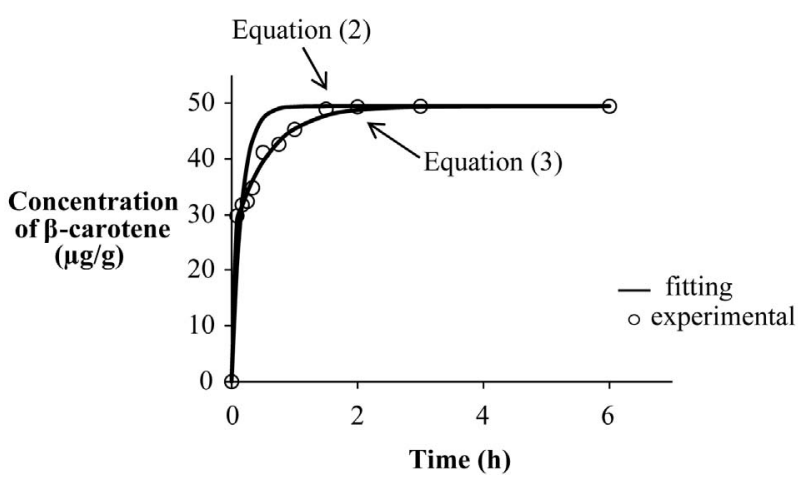

Figure 2. Comparison of one-term and two-term diffusion model (Equations (2) and (3)) to describe kinetics of extraction of $\beta$-carotene for carrots at $50^{\circ} \mathrm{C}$ and $35 \mathrm{MPa}$.

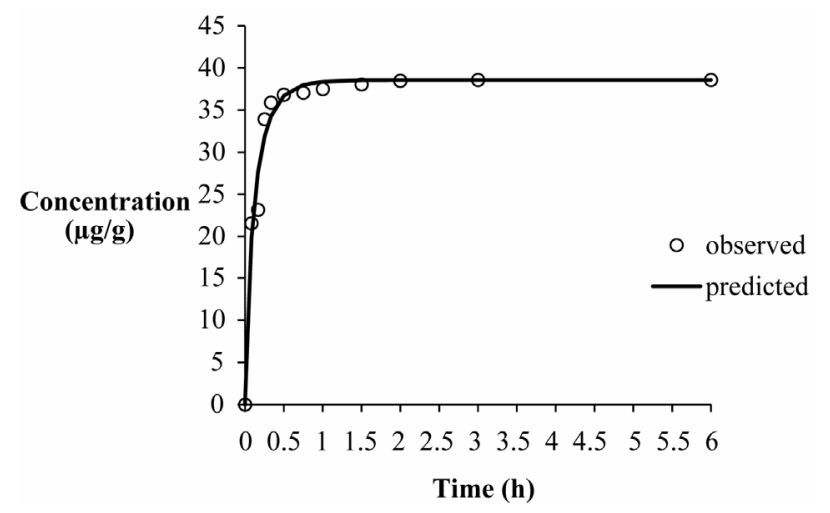

Figure 3. Weibull distribution model to describe kinetics of extraction of $\beta$-carotene for carrots at $50^{\circ} \mathrm{C}$ and $35 \mathrm{MPa}$.

Table 1. Values of coefficients of regression analysis of Equation (3) at $30 \mathrm{MPa}$.

\begin{tabular}{ccccccc}
\hline $\begin{array}{c}\text { Temperature } \\
\left({ }^{\circ} \mathrm{C}\right)\end{array}$ & $\mathrm{k}_{1}$ & $\mathrm{f}_{1}$ & $\mathrm{k}_{2}$ & $\mathrm{f}_{2}$ & S.E. & $\mathrm{R}^{2}$ \\
\hline 40 & 20.52 & -0.70 & 1.79 & -0.29 & 0.00394 & 0.996 \\
50 & 211.00 & -0.30 & 3.07 & -0.69 & 0.00564 & 0.994 \\
55 & 233.38 & -0.61 & 1.41 & -0.38 & 0.00071 & 0.999 \\
\hline
\end{tabular}

ness of the mathematical models should be decided on 
the basis of fitting of data set at all experimental conditions as well as simplicity of their use. Equation (4) has only two coefficients while Equation (3) contains four coefficients. Weibull distribution model Equation (4) was therefore selected as the most appropriate model to describe the kinetics of extraction of $\beta$-carotene from carrots. The coefficients of regression of Equation (4) are reported in Tables 2-4.

\subsection{Effect of Temperature on Extraction of $\beta$-Carotene}

Concentration of $\beta$-carotene in the crude extract at any given time increased with temperature (Figure 4). This is due to increased mass transfer rate with temperature. The increase in temperature ensures the enhancement of the vapor pressure of extractable sample than the reduction in the solvent density, due to which the overall extraction yield increases [1]. Variation of $\mathrm{k}$ and $\mathrm{n}$ with temperature was however not systematic (Tables 2-4).

\subsection{Effect of Pressure on Extraction of $\beta$-Carotene}

The concentration of $\beta$-carotene in the crude extract at any given instant increased with pressure (Figure 5). This may be due to the fact that solute vapor pressure in-

Table 2. Values of coefficients of regression analysis of Equation (4) at $30 \mathrm{MPa}$.

\begin{tabular}{ccccc}
\hline Temperature $\left({ }^{\circ} \mathrm{C}\right)$ & $\mathrm{k}$ & $\mathrm{n}$ & $\mathrm{S} . \mathrm{E}$ & $\mathrm{R}^{2}$ \\
\hline 40 & 2.549 & 0.498 & 0.007 & 0.991 \\
50 & 2.246 & 0.474 & 0.012 & 0.986 \\
55 & 2.328 & 0.462 & 0.017 & 0.982 \\
\hline
\end{tabular}

Table 3. Values of coefficients of regression analysis of Equation (4) at $35 \mathrm{MPa}$.

\begin{tabular}{ccccc}
\hline Temperature $\left({ }^{\circ} \mathrm{C}\right)$ & $\mathrm{k}$ & $\mathrm{n}$ & $\mathrm{S} . \mathrm{E}$ & $\mathrm{R}^{2}$ \\
\hline 40 & 2.375 & 0.464 & 0.019 & 0.979 \\
50 & 2.375 & 0.464 & 0.003 & 0.996 \\
55 & 2.399 & 0.368 & 0.007 & 0.990 \\
\hline
\end{tabular}

Table 4. Values of coefficients of regression analysis of Equation (4) at $40 \mathrm{MPa}$.

\begin{tabular}{ccccc}
\hline Temperature $\left({ }^{\circ} \mathrm{C}\right)$ & $\mathrm{k}$ & $\mathrm{N}$ & $\mathrm{S} . \mathrm{E}$ & $\mathrm{R}^{2}$ \\
\hline 40 & 2.527 & 0.496 & 0.002 & 0.997 \\
50 & 3.00 & 0.560 & 0.007 & 0.991 \\
55 & 2.321 & 0.355 & 0.006 & 0.992 \\
\hline
\end{tabular}

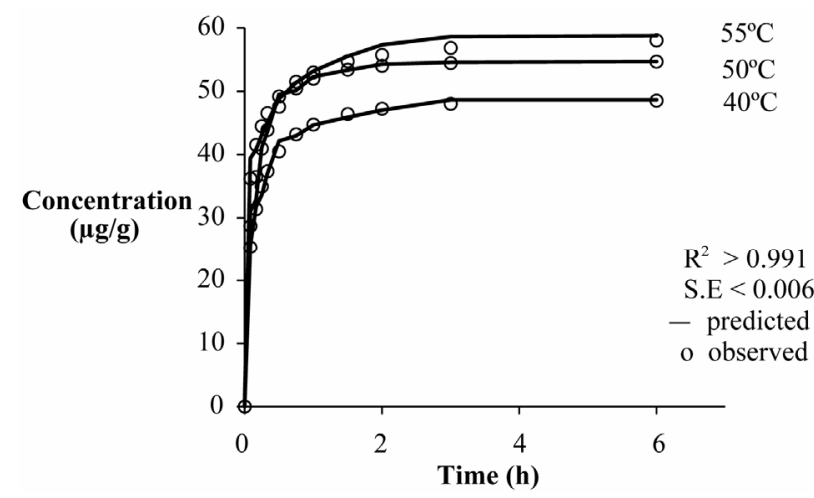

Figure 4. Effect of supercritical temperature on extraction of $\beta$-carotene at $40 \mathrm{MPa}$.

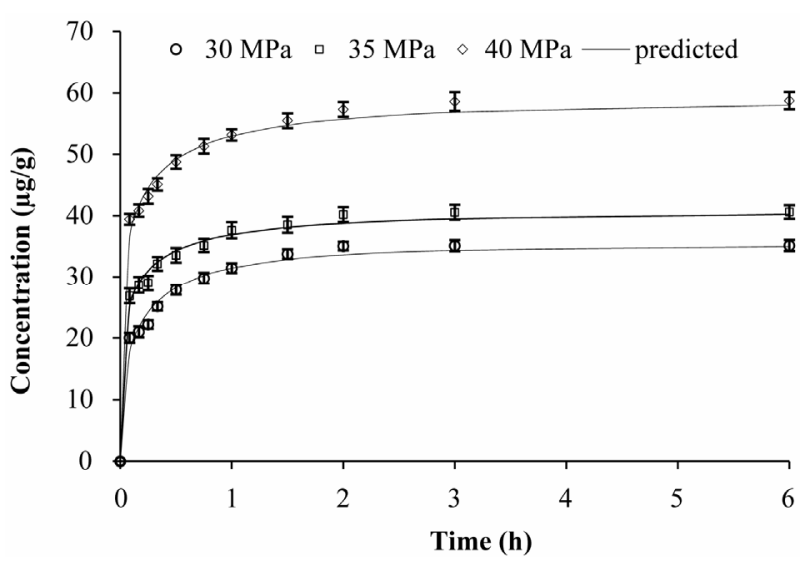

Figure 5. Effect of pressure on concentration of $\boldsymbol{\beta}$-carotene at supercritical temperature of $55^{\circ} \mathrm{C}$.

creased but solvent density decreased with increased supercritical pressure [9]. Variation of $\mathrm{k}$ and $\mathrm{n}$ with pressure was however not consistent.

\subsection{Effect of Supercritical $\mathrm{CO}_{2}$ Flow Rate on $\beta$-Carotene Concentration}

Yield of $\beta$-carotene was maximum when carrots were extracted at $45^{\circ} \mathrm{C}$ and $35 \mathrm{MPa}$ using $2 \mathrm{~L} / \mathrm{min} \mathrm{CO}_{2}$ flow rate. Effect of flow rate of the solvent on extraction of $\beta$-carotene was therefore investigated at the optimized condition of temperature and pressure. Effect of flow rate was investigated by extraction of $\beta$-carotene for $6 \mathrm{~h}$ at 2.0, 2.5 , and $3.0 \mathrm{~L} / \mathrm{min} \mathrm{CO}_{2}$ at $35 \mathrm{MPa}$ and $45^{\circ} \mathrm{C}$. Concentration of $\beta$-carotene in the extract increased with flow rate of $\mathrm{SC}-\mathrm{CO}_{2}$ from $2 \mathrm{~L} / \mathrm{min}$ to 2.5 and $3 \mathrm{~L} / \mathrm{min}$ (Figure 6). Similar behavior has been reported by several researches $[1,10]$.

\section{Conclusion}

In present study, effects of temperature, pressure, flow rate and extraction time on kinetics of $\beta$-carotene from tray dried carrots using SCFE technique was investigated. 


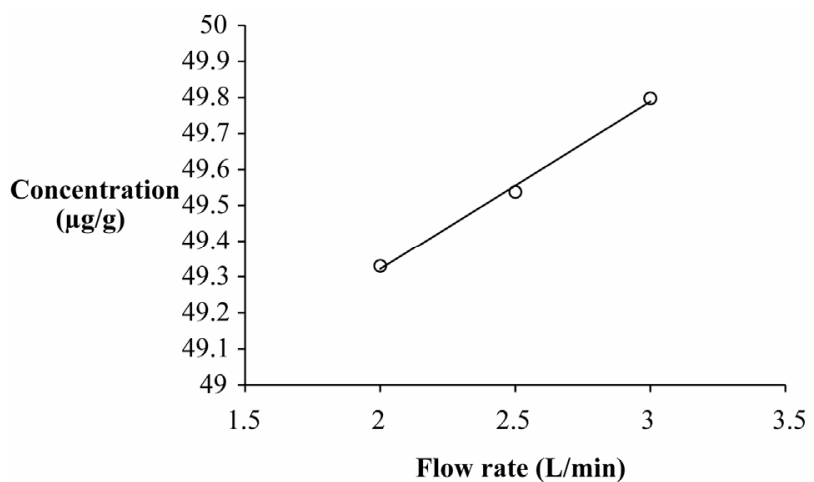

Figure 6. Effect of flow rate of $\mathrm{SC}-\mathrm{CO}_{2}$ on concentration of $\beta$-carotene from tray dried carrots at supercritical temperature of $45^{\circ} \mathrm{C}$ and $35 \mathrm{MPa}$ pressure (time of extraction = 6 h).

Mass of crude extract and $\beta$-carotene increased with time, temperature and pressure of extraction and was maximum when extraction was carried out at $45^{\circ} \mathrm{C}$ and 35 $\mathrm{MPa}$. It was established that it takes about $6 \mathrm{~h}$ for the SCFE process to reach equilibrium. Weibull model described adequately the supercritical extraction of $\beta$ - carotene from carrots. Variation of the rate constant $(\mathrm{k})$ with supercritical temperature and pressure was not consistent.

\section{REFERENCES}

[1] P. Subra, S. Castellani, P. Jestin and A. Aoufi, "Extraction of $\beta$-Carotene with Supercritical Fluids, Experiments and Modeling," Journal of Supercritical Fluids, Vol. 12, No. 3, 1998, pp. 261-269. doi:10.1016/S0896-8446(98)00085-0

[2] J. Velíšek, "Chemie Potravín (II). OSSIS, Tábor, Isolations and Formulations of Nutrient-rich Carotenoids,"
United States Patent: 6056962, 1999.

[3] I. S. M. Zaidul, N. N. A. Norulaini, A. K. M. Omar and R. L. Smith Jr., "Supercritical Carbon Dioxide $\left(\mathrm{SC}-\mathrm{CO}_{2}\right)$ Extraction and Fractionation of Palm Kernel Oil from Palm Kernel as Cocoa Butter Replacers Blend," Journal of Food Engineering, Vol. 73, No. 3, 2006, pp. 210-216. doi:10.1016/j.jfoodeng.2005.01.022

[4] G. Brunner, "Supercritical Fluids: Technology and Application to Food Processing," Journal of Food Engineering, Vol. 67, No. 1-2, 2005, pp. 21-33. doi:10.1016/j.jfoodeng.2004.05.060

[5] A. E. Brignole, "Supercritical Fluid Extraction," Fluid Phase Equilibria, Vol. 29, 1986, pp. 133-144. doi:10.1016/0378-3812(86)85017-8

[6] Q. Lang and M. Ch. Wai, "Supercritical Fluid Extraction in Herbal and Natural Product Studies - A Practical Review," Talanta, Vol. 53, No. 4-5, 2001, pp. 771-782. doi:10.1016/S0039-9140(00)00557-9

[7] M. Sun and F. Temelli, "Supercritical $\mathrm{CO}_{2}$ Extraction of Carotenoids from Carrots and Evaluation of Products," Journal of Supercritical Fluids, Vol. 37, No. 3, 2002, pp. 397-408. doi:10.1016/j.supflu.2006.01.008

[8] E. G. Oliveira, A. J. D. Silvestre and C. M. Silva, "Review of Kinetic Models for Supercritical Fluid Extraction," Chemical Engineering Research and Design, Vol. 89, No. 7, 2010, pp. 1104-1117.

[9] K. P. Johnston and C. A. Eckert, "An Analytical Carnahan-Starling-van der Waals Model for Solubility of Hydrocarbon Solids in Supercritical Fluids," AIChE Journal, Vol. 27, No. 5, 2004, pp. 773-779. doi:10.1002/aic.690270511

[10] O. Döker, U. Salgın, I. Sanal, U. Mehmetoglu and A. Çalıml1, "Modeling of Extraction of $\beta$-Carotene from Apricot Bagasse Using Supercritical $\mathrm{CO}_{2}$ in Packed Bed Extractor," Journal of Supercritical Fluids, Vol. 28, No. 1, 2003, pp. 11-19. 